\title{
The Vacuolar Transporter OsNRAMP2 Mediates Fe Remobilization During Germination and Affects Cd Distribution to Rice Grain
}

Jia-Dong Chang

Nanjing Agricultural University

Yun Xie

Nanjing Agricultural University

Huanhuan Zhang

Nanjing Agricultural University

Shurui Zhang

Nanjing Agricultural University

Fangjie Zhao ( $\nabla$ fangjie.zhao@njau.edu.cn )

Nanjing Agricultural University https://orcid.org/0000-0002-0164-169X

\section{Research Article}

Keywords: Cadmium, Iron, OsNRAMP2, Rice, Tonoplast, Transporter, mutations

Posted Date: January 3rd, 2022

DOI: https://doi.org/10.21203/rs.3.rs-1206604/v1

License: (c) (i) This work is licensed under a Creative Commons Attribution 4.0 International License.

Read Full License

Version of Record: A version of this preprint was published at Plant and Soil on February 25th, 2022. See the published version at https://doi.org/10.1007/s11104-022-05323-6. 


\section{Abstract}

Background and aims Iron ( $\mathrm{Fe}$ ) deficiency in plants is a common problem affecting agricultural production. Cadmium (Cd) is a toxic metal that can be taken up and transported within plants by transporters for divalent metals including Fe(II). The present study aims to investigate the functions of OsNRAMP2 (Natural Resistance-Associated Macrophage Protein 2) in the remobilization and distribution of Fe and $\mathrm{Cd}$ in rice.

Methods The expression pattern of OsNRAMP2 was determined by quantitative real-time PCR and pOsNRAMP2:GUS assay. Knockout mutants of OSNRAMP2 were generated by using CRISPR/Cas9 gene editing. Localization of $\mathrm{Fe}$ in the vacuolar globoids of germinating seeds was imaged by high-resolution transmission electron microscopy coupled with energy-dispersive X-ray spectroscopy. Distributions of Fe and $\mathrm{Cd}$ between different plant tissues were investigated in hydroponic and soil pot experiments.

Results OsNRAMP2 was mainly expressed in the embryo of germinating seeds, roots, leaf sheaths and leaf blades. OsNRAMP2 was localized at the tonoplast. Knockout of OsNRAMP2 delayed seed germination and produced chlorotic seedling leaves. Remobilization of Fe stored in the protein storage vacuoles in the scutellum of germinating seeds was restricted in osnramp2 mutants compared with wild type. Expression of genes related to Fe uptake was enhanced in the seedlings of osnramp2 mutants. Knockout of OsNRAMP2 significantly decreased the distribution of $\mathrm{Cd}$, but not Fe, from leaves and straws to rice grains.

Conclusions OsNRAMP2 plays an important role in remobilizing vacuolar Fe during seed germination and affects translocation of $\mathrm{Cd}$ from vegetative tissues to rice grains.

\section{Introduction}

Iron $(\mathrm{Fe})$ is an essential element for all living organisms. This transition metal plays a key role in electron transfer in both photosynthetic and respiratory reactions. Although there is abundant Fe in the Earth's crust, the bioavailability of $\mathrm{Fe}$ is often very limited and Fe deficiency occurs frequently both in humans and in crop plants that feed them (Takahashi et al. 2003). Iron deficiency-induced leaf chlorosis and plant growth retardation is a major agricultural problem globally (Ling et al. 1999; Gao et al. 2016).

Plants use different strategies to acquire Fe from the soil. Strategy I employed by dicotyledonous plants includes acidification of the rhizosphere, reduction of ferric iron [Fe(III)] to more soluble ferrous iron [Fe(II)] by membrane-bound Fe(III)-chelate reductases, and uptake of Fe(II) by membrane transporters such as IRT1 (Ishimaru et al. 2006; Cheng et al. 2007; Huang et al. 2020). Strategy II is employed only by graminaceous monocotyledonous species. In response to Fe deficiency, roots of strategy II plants secrete phytosiderophores, such as 2'-deoxymugineic acid (DMA), to chelate and mobilize Fe(III) in the rhizosphere, and subsequently take up $\mathrm{Fe}$ (III)-phytosiderophores complexes by transporters such as OsYSL15 (Yellow Stripe1-Like 15) in rice (Römheld and Marschner 1986; Inoue et al. 2009; Lee et al. 2009; Conte and Walker 2011). In Strategy II plants, nicotianamine (NA) synthase (NAS) and nicotianamine 
aminotransferase (NAAT) are two key enzymes in the biosynthesis of NA and its conversion to DMA (Kobayashi et al. 2010). NA not only is the precursor of DMA, but also plays an important role in the phloem transport of Fe by complexing Fe(III) (Takahashi et al. 2003). Rice osnaat1 mutants were not able to produce DMA and take up Fe(III) efficiently (Cheng et al. 2007; Inoue et al. 2008). Secretion of DMA is mediated by the plasma membrane transporter OsTOM1 (Transporter of Mugineic Acid 1) (Nozoye et al. 2011). Interestingly, rice appears to possess both strategies I and II (Cheng et al. 2007; Ishimaru et al. 2007). In flooded paddy soil, the major form of Fe in soil solution is Fe(II), which is present at relatively high concentrations due to reduction of Fe(III) under anoxic conditions (Wang et al. 2020). Uptake of Fe(II) may be mediated by OsIRT1 and OsIRT2 (Iron-Regulated Transporter 1 and 2) in rice roots (Bughio et al. 2002; Ishimaru et al. 2006).

Because excess $\mathrm{Fe}$ is highly phytotoxic, cellular Fe concentration has to be regulated strictly (Akmakjian et al. 2021). Sequestration of Fe into the vacuoles via the transporters AtVIT1, OsVIT1 and OsVIT2 (Vacuolar Iron Transporter 1 and 2) is an important mechanism of cellular Fe homeostasis in Arabidopsis thaliana and rice (Kim et al. 2006; Zhang et al. 2012; Che et al. 2021). In addition, OsVIT2 also regulates the distribution of Fe to the grains by sequestering Fe in the vacuoles in the mestome sheath, nodes, and aleurone layer (Che et al. 2021). Synchrotron X-ray fluorescence imaging showed that Fe is preferentially accumulated in the vacuoles of the fundamental parenchyma cells of the nodes and internodes of rice plants (Moore et al. 2014). Conversely, both AtNRAMP3 and AtNRAMP4 (Natural Resistance-Associated Macrophage Protein 3 and 4) are localized at the tonoplast and play redundant roles in the efflux of the vacuolar Fe store to support early development or under Fe-limiting conditions (Lanquar et al. 2005). OsNRAMP2 in rice is a close homologue of AtNRAMP3 and AtNRAMP4 (Supplemental Fig. S1). A recent study showed that OsNRAMP2 is a vacuolar Fe efflux transporter and plays a role in Fe translocation from the vacuole to the cytosol of rice plants (Li et al. 2021).

Cadmium (Cd) is a highly toxic element for living organisms. Because $\mathrm{Cd}$ has a relatively high availability in soil, it is readily taken up by food crops, posing a risk to human health (Clemens 2019; McLaughlin et al. 2021; Zhao et al. 2021). Accumulation of $\mathrm{Cd}$ in rice grain is of particular concern, as rice is the major dietary source of Cd for Asian populations (Meharg et al. 2013; Song et al. 2017; Wang et al. 2019). Understanding how plants take up and transport $\mathrm{Cd}$ is imperative for developing strategies to reduce the risk of $\mathrm{Cd}$ accumulation in food crops, especially rice. Owing to similarities in the physicochemical properties, $\mathrm{Cd}$ can hitchhike on a number of Fe and Mn transporters, e.g. AtIRT1, AtIRT2, AtNRAMP1, OsNRAMP1 and OsNRAMP5 (Thomine et al. 2000; Vert et al. 2002; Cailliatte et al. 2010; Ishikawa et al. 2012; Sasaki et al. 2012; Yang et al. 2014; Castaings et al. 2016; Chang et al. 2020a, b). Meanwhile, another key player that affects Cd translocation is OsHMA3 (Heavy Metal ATPases 3), which is a tonoplast transport responsible for the vacuolar sequestration of Cd (Ueno et al. 2010; Miyadate et al. 2011; Yan et al. 2016; Sui et al. 2019). Previous studies using heterologous expression in yeast also suggested that OsNRAMP2 has a transport activity for Cd (Zhao et al. 2018; Li et al. 2021). Whether OsNRAMP2 participates in the distribution of $\mathrm{Cd}$ in rice plants has not been elucidated. 
In the present study, we performed detailed functional analysis of OsNRAMP2 with regard to its roles in Fe remobilization and Cd distribution in rice. We show that OsNRAMP2 plays a crucial role in Fe remobilization from vacuoles during seed germination and also contributes to Cd distribution to rice grains.

\section{Materials And Methods}

\section{Plant materials and growth conditions}

Rice (Oryza sativa L.) cultivar Nipponbare was used for gene expression experiments. Knockout lines of osnramp2 were generated in the background of cv. Zhonghua11 (ZH11) using CRISPR/Cas9 technology as described below.

For hydroponic experiments, seeds were soaked in water for two days at $37^{\circ} \mathrm{C}$ in the dark and then transferred to a black net floating on water. One week later, seedlings were transferred to 6-L plastic pots (24 plants per pot) containing $1 / 2$ Kimura B solution (Chang et al. 2020a). The composition of the nutrient

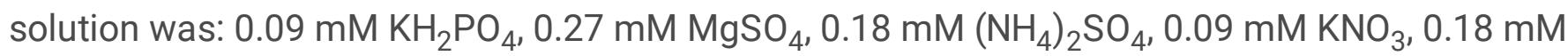
$\mathrm{Ca}\left(\mathrm{NO}_{3}\right)_{2}, 3.0 \mu \mathrm{M} \mathrm{H}_{3} \mathrm{BO}_{3}, 0.5 \mu \mathrm{M} \mathrm{MnCl}_{2}, 1.0 \mu \mathrm{M}\left(\mathrm{NH}_{4}\right)_{6} \mathrm{Mo}_{7} \mathrm{O}_{24}, 0.4 \mu \mathrm{M} \mathrm{ZnSO}_{4}, 0.2 \mu \mathrm{M} \mathrm{CuSO}_{4}$, and $20 \mu \mathrm{M}$ $\mathrm{Fe}(\mathrm{III})$-EDTA. The $\mathrm{pH}$ of this solution was buffered at around 5.6 with $2 \mathrm{mM}$ MES [2-(N-morpholino)ethane sulphonic acid] buffer, and the nutrient solution was renewed every three days. Plants were grown in a growth room with a light intensity of approximately $400 \mu \mathrm{mol} \mathrm{m}^{-2} \mathrm{~s}^{-1}$ (sodium vapour lamps) under a photoperiod of $12 / 12 \mathrm{~h}$ at $30 / 25^{\circ} \mathrm{C}$.

\section{Vector constructions and generation of transgenic plants}

To generate osnramp2 mutants, knockout vectors of OsNRAMP2 were constructed using a CRISPR/Cas9 expression getaway system (Miao et al. 2013). The target sequences were mutated in the first exon of the coding region of OsNRAMP2 (LOC_Os03g11010) (Supplemental Fig. S2). Specific target sequences were constructed on the sgRNA expression cassettes of OsU3 and cloned into the binary vector pOs-Cas9 by the LR Clonase (Invitrogen). To investigate tissue-specific expression pattern of OsNRAMP2, a $1885 \mathrm{bp}$ promoter sequence upstream of the start codon of OSNRAMP2 was amplified from the Nipponbare genomic DNA. The fragment containing pOsNRAMP2, the GUS coding sequence and NOS terminatorwere cloned into the pCAMBIA1301 vector at the Kpnl and Ncol sites using CloneExpress MultiS One Step Cloning Kit (Vazyme, Nanjing). All constructs were transformed into the calluses of wild-type rice (cv. ZH11) by Agrobacterium-mediated transformation (Hiei et al. 1997). Transgenic lines were selected by hygromycin resistance and verified by sequencing. T2 or T3 generations of homozygous transgenic lines were used in the experiments described below. Three independent lines of osnramp2 knockout were obtained (Supplemental Fig. S1B). In some experiments, only two of the mutant lines were used due to limited availability of seeds.

\section{Gene expression analysis}


To investigate the expression pattern of OsNRAMP2 in different tissues at different growth stages, CDNA was prepared from rice plants (cv Nipponbare) grown in a paddy field. To investigate the effects of $\mathrm{Cd}$ treatment or trace metal deficiency on OsNRAMP2 expression, 21-day-old seedlings (cv. Nipponbare) were transferred to $1 / 2$ Kimura B nutrient solution without $\mathrm{Zn}, \mathrm{Mn}$, Fe or $\mathrm{Cu}$, or containing $0.5 \mu \mathrm{M} \mathrm{CdCl}_{2}$ for 7 days. Roots and shoots were used for RNA extraction and cDNA preparation as described previously (Chang et al. 2020b).

To investigate the effect of knockout of OsNRAMP2 on the expression of Fe transport related genes, 14-day-old osnramp2 mutantsand wild type plants were grown in $1 \frac{1}{2}$ Kimura B nutrient solutions containing $0,0.2$ or $20 \mu \mathrm{M}$ EDTA-Fe(III) for 21 days. Three biological replicates were included for each treatment. At the end of experiment, roots were sampled for RNA extraction. The expression levels of OsNRAMP2, OsIRT1, OsIRT2, OsYSL15, OsTOM1, OsNAS1 and OsNAAT1 were quantified using an AceQTM qPCR SYBR Green Master Mix (Vazyme, Nanjing) on a BioRad CFX96. a-tubulin was used as the internal reference. The primer sequences used are shown in Supplemental Table S1.

\section{Subcellular localization of OsNRAMP2}

The full-length coding sequence of OSNRAMP2 without the stop codon was amplified by PCR and inserted between the CaMV35S promoter and eGFP-NOS terminator in the pSAT6A-eGFP vector. The OsNRAMP2-eGFP, eGFP-OsNRAMP2 and eGFP alone constructs were then introduced into the rice protoplasts by polyethylene-glycol method (Zhang et al. 2011). The MADS3-mCherry fusion protein was used as a nucleus marker (Gao et al. 2014). After incubation of protoplasts at $28{ }^{\circ} \mathrm{C}$ in the dark for $20 \mathrm{~h}$, fluorescence signals were detected using a confocal laser scanning microscope (TCS SP8 X, Leica).

\section{Phenotypic characterization of osnramp2 mutants}

To evaluate the effect of OsNRAMP2 mutation on seed germination, seeds of osnramp2 (two independent lines) and wild type were soaked in tap water for three days at $37^{\circ} \mathrm{C}$ in the dark. Water was renewed every day. Germination rates were determined after 3 days.

To investigate the effect of Fe supply on growth phenotypes, 14-day-old osnramp2 (two independent lines) and wild type plants were grown in $1 / 2$ Kimura $B$ nutrient solution containing $0,0.2$ or $20 \mu \mathrm{M}$ EDTAFe(III) for 21 days. Each genotype had four biological replicates. At the end of experiment, roots were washed with tap water and deionized water for three times, and roots and shoots were separated. Plant samples were dried at $65^{\circ} \mathrm{C}$ for 3 days and ground to fine powders. Samples were digested with $\mathrm{HNO}_{3} / \mathrm{HClO}_{4}(85: 15, \mathrm{v}: \mathrm{v})$ in a heating block. The concentrations of metals in the digests were determined by inductively coupled plasma mass spectrometry (ICP-MS, PerkinElmer Nexlon 300x).

To investigate the effect of knockout of OsNRAMP2 on root phenotypes, 14-day-old plants of osnramp2 (two independent lines) and wild type were grown in $1 / 2$ Kimura B nutrient solution containing 0 , 0.2 or $20 \mu \mathrm{M}$ EDTA-Fe(III) for 21 days. Each genotype and Fe treatment were replicated four times. Roots 
of individual plants were imaged using a scanner (LA2400 Scanner, Canada). Total root length, total surface area, and numbers of tips were quantified using WinRHIZO software (WinRHIZO 2019a, Canada).

\section{Electron microscopy and microanalysis}

To investigate localization of $\mathrm{Fe}$ in the vacuolar globoids during seed germination, seeds of osnramp2 mutants and wild type were soaked in water at $37^{\circ} \mathrm{Cfor} 3$ days. The localization of Fe in the vacuolar globoids was characterized using high-resolution transmission electron microscopy coupled with energydispersive X-ray spectroscopy and selected area electron diffraction (HRTEM-EDX-SAED) according to the method described previously (Lanquar et al. 2005; Jiang et al. 2021). Briefly, geminated seeds were chilled and fixed in $2.5 \%(\mathrm{v} / \mathrm{v})$ triple distilled glutaraldehyde in $0.1 \mathrm{M}$ phosphate buffer (PBS, pH 7.4) at $4.0^{\circ} \mathrm{C}$ for $24 \mathrm{~h}$. The samples were fixed again with $1 \%(\mathrm{v} / \mathrm{v})$ osmic acid and $0.1 \mathrm{M} \mathrm{PBS}(\mathrm{pH} 7.4)$ at room temperature for 2 hours. Finally, they were rinsed by $0.1 \mathrm{M} \mathrm{PBS}(\mathrm{pH} 7.4)$ three times (15 min each). The samples were embedded in resin and ultrathin sections with a thickness of $100 \mathrm{~nm}$ were cut using a Leica EM UC7 Ultramicrotome with a diamond knife (Diatome, Ultra $45^{\circ}$ ). The thin sections were observed under a transmission electron microscope equipped with an energy filter (Tecnai $\mathrm{G}^{2} \mathrm{~F} 20$ system, $\mathrm{FEI}, \mathrm{USA}$ ) and an Energy-dispersive X-ray (EDX) spectroscopy (Aztec X-Max 150, Oxford, UK). For ESI (imaging of inelastically scattered electrons), images were captured using a slow-scan charge-coupled device (CCD) camera attached on an image filter (Gatan GIF 2000). For Fe colorization of TEM Images, the ESI images of Fe were background-subtracted, colored and superimposed on the transmission image.

\section{Effect of knockout of OsNRAMP2 on Cd accumulation}

To test the effects of knockout of OsNRAMP2 on Cd accumulation in rice, two independent mutation lines and wild type plants (21-day-old) were transferred to $1 / 2$ Kimura $B$ nutrient solutions containing 0.5 or 1.0 $\mu \mathrm{M}$ Cd for 10 days. Each genotype had four biological replicates. The concentrations of $\mathrm{Cd}$ in roots and shoots were determined by ICP-MS. To determine Cd concentration in the xylem sap, rice seedlings (28day-old) of two osnramp2 lines and wild type were transferred to $1 \frac{1}{2}$ Kimura B nutrient containing $1.0 \mu \mathrm{M}$ $\mathrm{Cd}$ for $12 \mathrm{~h}$. Each genotype had four biological replicates. Stems were cut at 2-3 cm above the shoot-root junction, cleaned with deionized water and wrapped with an absorbent cotton ball. Xylem exudate was collected into the cotton ball for $4 \mathrm{~h}$ and centrifuged at 12,000 $\mathrm{g}$ for $10 \mathrm{~min}$. Xylem sap was diluted with $2 \% \mathrm{HNO}_{3}$ before determination of $\mathrm{Cd}$ concentration by ICP-MS.

\section{Soil pot experiment}

A Cd-contaminated paddy soil was collected from a paddy field in Deyang, Sichuan Provence, China. The soil contained $3.4 \mathrm{mg} \mathrm{Cd} \mathrm{kg}^{-1}$ and $\mathrm{pH}$ was 6.0 . One seedling each of three osnramp2 mutant lines and wild type were transplanted in a 15-L plastic pot filled with $8 \mathrm{~kg}$ soil. Four pots were prepared to represent four biological replicates. The experiment was conducted inside a net enclosure with natural sunlight and ambient temperature during the summer season of 2020. Tap water was used to flood the soil and maintain a $3-5 \mathrm{~cm}$ water level above the soil surface during the period of vegetative growth. Soil was 
maintained at moist but unflooded conditions during the grain filling period. Plants were harvested at grain maturity. The concentrations of $\mathrm{Cd}$ and Fe in grains and straws were determined by ICP-MS.

\section{Statistical analysis}

Data were analyzed by one-way ANOVA, followed by comparisons of means using Tukey's test at $P<$ 0.05. Statistical analyses were performed using OriginPro 2021.

\section{Results}

\section{Expression pattern of OsNRAMP2}

Quantitative reverse transcription PCR (Q-RT-PCR) was used to determine the expression levels of OsNRAMP2 in various tissues of rice plants (cv. Nipponbare) grown in a paddy field at different growth stages. At the seedling, tillering, booting and flowering stages, OsNRAMP2 was mainly expressed in the roots, leaf sheaths and leaf blades (Fig. 1A). The expression levels of OsNRAMP2 in the leaf sheaths and leaf blades were higher than those in the rootsand stems at all growth stages. The expression level of OsNRAMP2 in the leaf sheaths and leaf blades generally increased with growth stage with a peak at the flowering stage (Fig. 1A).

The responses of OsNRAMP2 transcript level to withdrawal of micronutrients $\mathrm{Fe}, \mathrm{Zn}$ and $\mathrm{Cu}$ or the addition of $\mathrm{Cd}$ were investigated in a hydroponic experiment. Withdrawal of Fe for 7 days slightly induced the expression of OsNRAMP2 in roots, whereas other treatments had little effect (Fig. 2B). The response to Fe deficiency was further investigated in a time-course experiment. In both roots and shoots, OsNRAMP2 expression was induced by Fe deficiency from day 2 onward, with a 1.75- and 2-fold increase, respectively, on day 5 of Fe withdrawal compared with the +Fe treatment on day 0 (Fig. 2C).

\section{Tissue specificity and subcellular localization of OsNRAMP2}

To investigate the tissue and cell specificity of OsNRAMP2 expression, we generated transgenic rice (cv. $\mathrm{ZH} 11$ ) expressing the GUS reporter gene under the control of the native promoter of OsNRAMP2. Histochemical staining of the GUS activity in the pOsNRAMP2::GUS transgenic lines showed that OsNRAMP2 was expressed mainly in the radicle and embryo of germinated seeds, as well as roots, leaf sheaths and leaf blades of seedings (Fig. 2A, B, C, H). Consistent with the Q-RT-PCR data, withdrawal of Fe from the nutrient solution for 7 days slightly increased the GUS activity in the roots (Fig. 2D, E, F, G). The GUS activity was localized in all root cells, as well as in the leaf mesophyll cells and the parenchyma cells surrounding the vascular bundles in the leaf sheaths (Fig. 2F, G, I).

To determine the subcellular localization of OsNRAMP2, OsNRAMP2-eGFP or eGFP-OsNRAMP2 was transiently expressed in rice protoplasts driven by the CaMV35S promoter. MADS3-mCherry fusion protein was used as a nucleus marker (Gao et al. 2014). In the control expressing eGFP alone, the GFP signal was detected in the cytoplasm, whereas the GFP signal in the protoplasts expressing OsNRAMP2-eGFP or eGFP-OSNRAMP2 was observed at the tonoplast with the nucleus marked by MADS3-mCherry being 
outside of the GFP signal (Fig. 3). Fusion of GFP to the N- or C-terminal of OsNRAMP2 revealed the same subcellular localization at the tonoplast.

\section{Knockout of OsNRAMP2 inhibited germination and suppressed remobilization of vacuolar Fe during seed germination}

Knockout of OsNRAMP2 delayed seed germination (Fig. 4A, B). After 3 days of soaking at $37^{\circ} \mathrm{C}$, two osnramp2 mutants had a germination rate of $21.2-27.2 \%$, compared with $86.4 \%$ in wild type (Fig. $4 \mathrm{C}$ ). After seedlings were grown in tap water for 8 days, shoot height of osnramp2 mutants was $39.3 \%$ shorter than that of wild type (Fig. 4D). Moreover, osnramp2 mutants displayed leaf chlorotic symptoms typical of Fe deficiency (Fig. 4D). The concentrations of Fe in the shoots and roots of the osnramp2 mutants were significantly $(P<0.05)$ lower, by $41.2-46.9 \%$ and $41.9-47.8 \%$, respectively, than wild type (Fig. 4E). The lower Fe concentrations in the mutant seedlings were not attributed to lower Fe concentrations in the seeds, because there was no significant difference in seed Fe concentration between mutants and wild type (Fig. 4F).

To investigate whether knockout of OsNRAMP2 affects Fe remobilization during germination, we used electron microscopy coupled to energy dispersive X-ray (EDX) spectra to image the distribution of Fe in the scutellum cells of germinated seeds. In both wild type and osnramp2, Fe was localized to the electron dense globoids inside the protein bodies (i.e. protein storage vacuoles, Fig. 4G, H) in scutellum cells, which was confirmed by EDX analysis of individual globoids (Fig. $4 \mathrm{~L}$ and M). This pattern of Fe localization is similar to that reported for germinated seeds of Arabidopsis thaliana (Lanquar et al. 2005). Compared with wild type, osnramp2 mutant showed more Fe-containing globoids inside vacuoles (Fig. $4 \mathrm{I}$ and $\mathrm{K}$ ), suggesting that remobilization of Fe from the protein storage vacuoles during germination is restricted in the mutant.

\section{osnramp2 mutants were more sensitive to Fe deficiency at the seedling stage}

Seedlings (14-day-old) of two osnramp2 mutants and wild type were grown in nutrient solution containing $0,0.2$ or $20 \mu \mathrm{M}$ Fe for 21 days. Under low Fe $(0.2 \mu \mathrm{M})$ or no Fe conditions, osnramp2 mutants grew more poorly than wild type, with significantly shorter root length and shoot height (Figs. 5A, B). Total root length, root surface area and the number of root tips (including both primary and lateral roots) of the mutants were all significantly $(P<0.05)$ smaller than those of wild type (Figs. 5B, Supplemental S3AS3E). The youngest fully developed leaves of the mutant lines were chlorotic (Fig. 5A), and the chlorophyll content (SPAD value) was significantly lower than wild type (Fig. 5C). Meanwhile, knockout of OsNRAMP2 significantly decreased plant total biomass (Fig. 5D). Surprisingly, osnramp2 mutants contained significantly higher concentrations of $\mathrm{Fe}$ in roots and shoots than wild type under low $\mathrm{Fe}$ or no Fe treatments (Fig. 5E, F). Supply of $20 \mu \mathrm{M}$ Fe alleviated the chlorotic symptoms of osnramp2 mutants and improved their growth, although leaf chlorophyll content and plant biomass were still smaller than wild type (Fig. 5A, C, D). In addition, there was no significant difference in either shoot or root Fe concentration between mutants and wild type in the $20 \mu \mathrm{M}$ Fe treatment (Fig. 5E, F). 


\section{Knockout of OsNRAMP2 increased the expression of Fe transport related genes}

Higher concentrations of Fe in the roots and shoots of osnramp2 mutants could be an indirect result from altered expression of genes involved in Fe uptake and transport. To test this hypothesis, we quantified the expression of OsIRT1, OsIRT2, OsYSL 15, OsTOM1, OsNAS1 and OsNAAT1 in the roots of mutants and wild type grown under different $\mathrm{Fe}(0,0.2$ and $20 \mu \mathrm{M})$ supply conditions for 21 days. As expected, low Fe or no Fe conditions increased the expression of OSIRT1, OSIRT2, OSYSL15, OsTOM1, OSNAS1 and OsNAAT1 markedly (Fig. 6A-F). Moreover, osnramp2 mutants showed significantly higher expression of OSIRT1 and OSYSL15 than wild type under all Fe supply conditions (Fig. 6A-C). In addition, knockout of OsNRAMP2 significantly increased the expression of OsTOM1, OsNAS1, and OsNAAT1 in either normal or the low Fe conditions (Fig. 6D-F).

\section{Knockout of OSNRAMP2 decreased Cd translocation to and accumulation in rice grain}

To test whether OsNRAMP2 is involved in Cd distribution, seedlings (21-day-old) of two osnramp2 mutants and wild type were grown in nutrient solution containing 0.5 or $1.0 \mu \mathrm{M} \mathrm{Cd}$ for 10 days. There were no significant differences in the growth phenotypes including root length and shoot height between mutants and wild type (Supplemental Fig. 45A-C). Knockout of OsNRAMP2 had no significant effect on the concentrations of $\mathrm{Cd}$ in the roots and shoots at $0.5 \mu \mathrm{M} \mathrm{Cd}$ (Fig. 7A, B). At $1.0 \mu \mathrm{M} \mathrm{Cd}$, the concentrations of $\mathrm{Cd}$ in the roots and shoots of two osnramp2 lines were significantly $(P<0.05)$ lower than those of wild type by $20.4-22.7 \%$ and $11.6-13.9 \%$, respectively (Fig. 7A, B). After exposure to 1.0 $\mu \mathrm{M}$ Cd for $12 \mathrm{~h}$, xylem sap collected from two osnramp 2 mutants also contained significantly lower concentrations of $\mathrm{Cd}$ than that from wild type (Fig. 7C).

To examine the effect of knockout of OsNRAMP2 on Cd accumulation in rice grain, three osnramp2 mutant lines and wild type were grown in a Cd-contaminated paddy soil in a pot experiment. At maturity, there was no significant difference in plant height between osnramp2 mutants and wild type (Fig. 8A). However, knockout of OsNRAMP2 decreased straw biomass and grain yield by $47.3-59.7 \%$ and 31.5 $-47.0 \%$, respectively, compared with wild type (Fig. 8B, C). Grain Cd concentration in wild type was well over the Chinese permissible limit of $0.2 \mathrm{mg} \mathrm{kg}^{-1}$. Knockout of OsNRAMP2 significantly decreased grain Cd concentration by 21.0 - 23.9\% compared with wild type (Fig. 8D). In contrast, Cd concentrations in the flag leaves, leaf sheaths and straws of osnramp2 mutants were significantly higher than those of wild type (Fig. 8E, F, G). In contrast, knockout of OsNRAMP2 did not significantly affect the concentrations of Fe in the grains, flag leaves, leaf sheaths or straws, although there was a tendency for higher concentrations in the flag leaves, leaf sheaths and straws of mutants (Fig. 8H-L).

\section{Discussion}

The NRAMP family transporters have diverse subcellular localization and transport functions. For example, AtNRAMP1 is a plasma membrane transporter functioning on the uptake of $\mathrm{Fe}, \mathrm{Mn}$ and $\mathrm{Cd}$ (Cailliatte et al. 2010; Castaings et al. 2016). OsNRAMP1 and OsNRAMP5 are plasma membrane 
transporters important for the influx of $\mathrm{Mn}$ and Cd into root cells (Ishikawa et al. 2012; Sasaki et al. 2012; Yang et al. 2014; Chang et al. 2020a, b). AtNRAMP2 is a resident protein in the trans-Golgi network and functions in the remobilization of $\mathrm{Mn}$ in the Golgi for root growth under Mn-deficient conditions (Alejandro et al. 2017; Gao et al. 2018). AtNRAMP3 and AtNRAMP4 are two major efflux transporters localized at the tonoplast to mobilize vacuolar Fe during seed germination of $A$. thaliana (Lanquar et al. 2005). Recently, OsNRAMP2 has also been shown to be a tonoplast transporter involved in Fe efflux from vacuoles in rice ( $\mathrm{Li}$ et al. 2021). Our study provides further evidence that OsNRAMP2 participates in Fe remobilization from vacuolar metal stores during seed germination and also affects $\mathrm{Cd}$ distribution to rice grain.

OsNRAMP2 is highly expressed in the radicles and embryonal of germinated seeds, as well as in leaf sheaths and leaf blades (Fig. 2), and encodes a protein localized at the tonoplast (Fig. 3). The most noticeable phenotypes of osnramp2 mutants compared with wild type are delayed seed germination and chlorotic leaves in young seedlings grown under no Fe or low Fe conditions (Figs. 4 and 5). The chlorotic symptoms of the mutants could be alleviated by growing seedlings under a normal level of Fe supply (20 $\mu \mathrm{M})$. Because Fe concentrations in the seeds of osnramp2 mutants were similar, the phenotypes are likely caused by an inefficient remobilization of the Fe stored in the mutant seeds. Microanalysis of Fe using HRTEM-EDX-SAED showed that more Fe-rich globoids remained in the protein storage vacuoles in the scutellum in the germinating seeds of osnramp2 than wild type (Fig. 4), supporting the notion that Fe remobilization from the vacuoles is impaired in the mutants. Because Fe-containing heme is a key component of cytochrome c, an electron carrier in the respiratory chain (Roschzttardtz et al. 2009; Bastow et al. 2018), inefficient Fe remobilization could lead to low energy generation and delayed germination in the mutants. Compared with wild type, roots of osnramp2 young seedlings showed markedly enhanced expression of a number of genes involved in both the strategies I and II pathways, especially under low Fe supply (Fig. 6), indicating that the mutants experienced more acute Fe deficiency. Enhanced expression of Fe acquisition-related genes in the mutants could lead to more uptake of Fe available in the growth medium. This could partly explain higher Fe concentrations in the roots and shoots of mutant seedlings under low Fe conditions (Fig. 5). Alternatively, the higher Fe concentrations could also be attributed to smaller plant biomass of the mutant seedlings.

Despite OsNRAMP2 being also highly expressed in the leaf sheaths and leaf blades, distribution of Fe between leaves and grains was not significantly affected (Fig. 8). These results suggest that OsNRAMP2 plays relatively little role in remobilizing $\mathrm{Fe}$ in the leaf vacuoles for translocation to the grains. This is not surprising, because Fe in vegetative tissues is relatively immobile, and re-translocation of Fe from one shoot tissue or plant part to another is negligible (Lieten 2001; Sawyer 2004). A possible reason is that Fe stored in the vacuoles may be precipitated with phosphate, as demonstrated by strong colocalization of Fe and phosphate in the vacuoles of fundamental parenchyma cells in the nodes and internodes of rice plants (Moore et al. 2014). In this regard, the form of Fe stored in the protein storage vacuoles in the embryo may be more mobile to allow remobilization during germination. 
Because of similarities in physicochemical properties, Cd can be transported by some Fe(II) transporters, such as IRT1 (Vert et al. 2002). There is also some evidence that AtNRAMP3 and AtNRAMP4 can mediate Cd efflux out of the vacuoles in Arabidopsis (Thomine et al. 2000; Pottier et al. 2015). The Cd transport activity of OsNRAMP2 was demonstrated by heterologous expression assays in yeast (Zhao et al. 2018; Li et al. 2021). In the present study, knockout of OsNRAMP2 significantly decreased grain $\mathrm{Cd}$ concentration but increased the concentrations of $\mathrm{Cd}$ in leaves and straws (Fig. 8), suggesting that OsNRAMP2 also mediates $\mathrm{Cd}$ efflux from the vacuoles in the vegetative tissues for translocation to grains. In contrast to $\mathrm{Fe}, \mathrm{Cd}$ is much more mobile and can be readily redistributed within plants (Uraguchi and Fujiwara 2013; Zhao and Wang 2020). This difference probably explains why knockout of OsNRAMP2 affects the distribution of Cd but not Fe. The effect of OsNRAMP2 knockout on Cd translocation from roots to shoots was limited (Fig. 7), possibly because OsNRAMP2 was not strongly expressed in roots. It has been well established that OsHMA3 mediates $\mathrm{Cd}$ influx into the vacuoles and its activity is a key determinant controlling $\mathrm{Cd}$ translocation from roots to shoots and grains of rice (Ueno et al. 2010; Miyadate et al. 2011; Yan et al. 2016; Sui et al. 2019). Thus, OsNRAMP2 and OsHMA3 act in the opposite directions to control $\mathrm{Cd}$ sequestration in the vacuoles. In a genome-wide association study, Zhao et al. (2018) identified a QTL for grain Cd with OsNRAMP2 being within the region of this QTL. Whether OsNRAMP2 is the causal gene for this grain Cd QTL remains to be investigated. It would also be interesting to investigate whether allelic variations in OsNRAMP2 among rice cultivars affect the $\mathrm{Cd}$ transport activity and $\mathrm{Cd}$ translocation to rice grains.

In conclusion, the present study provides further evidence that OsNRAMP2 plays an important role in remobilizing vacuolar Fe during seed germination. Furthermore, our study reveals a new role of OsNRAMP2 in Cd distribution from vegetative tissues to rice grains.

\section{Declarations}

\section{Acknowledgements}

The work was supported by the Key Research and Development Program of Jiangsu province (BE2021717). We thank Jiani Chen (State Key Laboratory for Mineral Deposits Research, Nanjing University) and Prof. Shiwei Guo (College of Resources and Environmental Sciences, Nanjing Agricultural University) for their technical assistance in the electron microscopy and microanalysis and root phenotypes analysis.

\section{References}

1. Alejandro S, Cailliatte R, Alcon C, Dirick L, Domergue F, Correia D, Castaings L, Briat JF, Mari S, Curie C (2017) Intracellular Distribution of manganese by the trans-Golgi network transporter NRAMP2 is critical for photosynthesis and cellular redox homeostasis. Plant Cell 29:3068-3084.

2. Akmakjian GZ, Riaz N, Guerinot ML (2021) Photoprotection during iron deficiency is mediated by the bHLH transcription factors PYE and ILR3. Proc Natl Acad Sci USA 118(40): e2024918118. 
3. Ueno D, Yamaji N, Kono I, Huang CF, Ando T, Yano M, Ma JF (2010) Gene limiting cadmium accumulation in rice. Proc Natl Acad Sci USA 107:16500-16505.

4. Bastow EL, Garcia de la Torre VS, Maclean AE, Green RT, Merlot S, Thomine S, Balk J (2018) Vacuolar iron stores gated by NRAMP3 and NRAMP4 are the primary source of iron in germinating seeds. Plant physiol 177(3):1267-1276.

5. Bughio N, Yamaguchi H, Nishizawa NK, Nakanishi H, Mori S (2002) Cloning an iron-regulated metal transporter from rice. J Exp Bot 53:1677-1682.

6. Cailliatte R, Schikora A, Briat J, Mari S, Curie C (2010) High-affinity manganese uptake by the metal transporter NRAMP1 is essential for Arabidopsis growth in low manganese conditions. Plant Cell 22:904-917.

7. Castaings $L$, Caquot A, Loubet S, Curie C (2016) The high-affinity metal transporters NRAMP1 and IRT1 team up to take up iron under sufficient metal provision. Sci Rep-UK 6:37222.

8. Chang JD, Huang S, Konishi N, Wang P, Chen J, Huang XY, Ma JF, Zhao FJ (2020a) Overexpression of the manganese/cadmium transporter OsNRAMP5 reduces cadmium accumulation in rice grain. $J$ Exp Bot 71:5705-5715.

9. Chang JD, Huang S, Yamaji N, Zhang WW, Ma JF, Zhao FJ (2020b) OsNRAMP1 transporter contributes to cadmium and manganese uptake in rice. Plant Cell Environ 43:2476-2491.

10. Che J, Yamaji N, Ma JF (2021) Role of a vacuolar iron transporter OsVIT2 in the distribution of iron to rice grains. New Phytol 230(3):1049-1062.

11. Conte SS, Walker EL (2011) Transporters contributing to iron trafficking in plants. Mol Plant 4:464476.

12. Cheng LJ, Wang F, Shou H, Huang F, Zheng L, He F, Li J, Zhao FJ, Ueno D, Ma JF, Wu P (2007) Mutation in nicotianamine aminotransferase stimulated the $\mathrm{Fe}(\mathrm{II})$ acquisition system and led to iron accumulation in rice. Plant Physiol 145(4):1647-57.

13. Clemens S (2019) Safer food through plant science: reducing toxic element accumulation in crops. J Exp Bot 70:5537-5557.

14. Gao H, Jin M, Zheng XM, Chen J, Yuan D, Xin Y, Wang M, Huang D, Zhang Z, Zhou K, Sheng P, Ma J, Ma W, Deng H, Jiang L, Liu S, Wang H, Wu C, Yuan L, Wan JM (2014) Days to heading 7, a major quantitative locus determining photoperiod sensitivity and regional adaptation in rice. Proc Natl Acad Sci USA 111(46):16337-16342.

15. Gao H, Xie W, Yang C, Xu J, Li J, Wang H, Chen X, Huang C (2018) NRAMP2, a trans-Golgi networklocalized manganese transporter, is required for Arabidopsis root growth under manganese deficiency. New Phytol 217:179-193.

16. Gao L, Chang JD, Chen R, Li H, Lu H, Tao L, Xiong J (2016) Comparison on cellular mechanisms of iron and cadmium accumulation in rice: prospects for cultivating Fe-rich but Cd-free rice. Rice 9(1):39.

17. Hiei Y, Komari T, Kubo T (1997) Transformation of rice mediated by Agrobacterium tumefaciens. Plant Mol Biol 35:205-218. 
18. Huang S, Wang P, Yamaji N, Ma JF (2020) Plant nutrition for human nutrition: Hints from rice research and future perspectives, Mol Plant 13(6):825-835.

19. Inoue H, Takahashi M, Kobayashi T, Suzuki M, Nakanishi H, Mori S, Nishizawa NK (2008) Identification and localisation of the rice nicotianamine aminotransferase gene OSNAAT1 expression suggests the site of phytosiderophore synthesis in rice. Plant Mol Biol 66:193-203.

20. Inoue H, Kobayashi T, Nozoye T, Takahashi M, Kakei Y, Suzuki K, Nakazono M, Nakanishi H, Mori S, Nishizawa NK (2009) Rice OsYSL15 is an iron-regulated iron(III)-deoxymugineic acid transporter expressed in the roots and is essential for iron uptake in early growth of the seedlings. $\mathrm{J}$ Biol Chem 284: 3470-3479.

21. Ishikawa $S$, Ishimaru $Y$, Igura $M$, Kuramata $M$, Abe $T$, Senoura $T$, Hase $Y$, Arao $T$, Nishizawa NK and Nakanishi H (2012) lon-beam irradiation, gene identification, and marker-assisted breeding in the development of low-cadmium rice. Proc Natl Acad Sci USA 109:19166-19171.

22. Ishimaru Y, Kim S, Tsukamoto T, Oki H, Kobayashi T, Watanabe S, Matsuhashi S, Takahashi M, Nakanishi H, Mori S, et al. (2007) Mutational reconstructed ferric chelate reductase confers enhanced tolerance in rice to iron deficiency in calcareous soil. Proc Natl Acad Sci USA 104:7373-7378.

23. Ishimaru Y, Suzuki M, Tsukamoto T, Suzuki K, Nakazono M, Kobayashi T, Wada Y, Watanabe S, Matsuhashi S, Takahashi M et al. (2006) Rice plants take up iron as an $\mathrm{Fe}^{3+}$-phytosiderophore and as $\mathrm{Fe}^{2+}$. Plant J 45:335-346.

24. Jiang Z, Sun D, Guan H, Sun Y, Li Z (2021) Transmission electron microscopy analysis on microbial ultrathin sections prepared by the ultra-low lead staining technique. Microsc Microanal 1-8.

25. Kim SA, Punshon T, Lanzirotti A, Li L, Alonso JM, Ecker JR, Kaplan J, Guerinot ML (2006) Localization of iron in Arabidopsis seed requires the vacuolar membrane transporter VIT1. Science 314:1295-1298.

26. Kobayashi T, Nakanishi H, Nishizawa NK (2010) Recent insights into iron homestasis and their application in graminaceous crops. Proc Jpn Acad Ser B Phys Biol Sci 86:900-913.

27. Lanquar V, Lelievre F, Bolte S, Hames C, Alcon C, Neumann D, Vansuyt G, Curie C, Schroder A, Kramer $\mathrm{U}$, Barbierbrygoo $\mathrm{H}$, Thomine $\mathrm{S}$ (2005) Mobilization of vacuolar iron by AtNRAMP3 and AtNRAMP4 is essential for seed germination on low iron. EMBO J 24:4041-4051.

28. Lee S, Chiecko JC, Kim SA, Walker EL, Lee Y, Guerinot ML, An G (2009) Disruption of OsYSL15 leads to iron inefficiency in rice plants. Plant Physiol 150(2):786-800.

29. Li Y, Li J, Yu Y, Dai X, Gong C, Gu D, Xu E, Liu Y, Zou Y, Zhang P, Chen X, Zhang W (2021) The tonoplast-localized transporter OsNRAMP2 is involved in iron homeostasis and affects seed germination in rice. J Exp Bot 72(13):4839-4852.

30. Lieten F (2001) Iron nutrition of strawberries grown in peat bags, Small Fruits Review 1(2):103-112.

31. Ling HQ, Koch G, Baumlein H, Ganal MW (1999) Map-based cloning of chloronerva, a gene involved in iron uptake of higher plants encoding nicotianamine synthase. Proc Natl Acad Sci USA 96:70987103. 
32. McLaughlin MJ, Smolders E, Zhao FJ, Grant C, Montalvo D (2021) Managing cadmium in agricultural systems. Adv Agron 166:1-129.

33. Meharg AA, Norton G, Deacon C, Williams P, Adomako EE, Price A, Zhu Y, Li G, Zhao FJ, McGrath S, Villada A, Sommella A, De Silva PMCS, Brammer H, Dasgupta T, Islam MR (2013) Variation in rice cadmium related to human exposure. Nviron Sci Tech 47:5613-5618.

34. Miao J, Guo D, Zhang J, Huang Q, Qin G, Zhang X, Wan J, Gu H, Qu LJ (2013) Targeted mutagenesis in rice using CRISPR-Cas system. Cell Res 23:1233-1236.

35. Miyadate H, Adachi S, Hiraizumi A, Tezuka K, Nakazawa N, Kawamoto T, Katou K, Kodama I, Sakurai K, Takahashi H, Satoh-Nagasawa N, Watanabe A, Fujimura T, Akagi H (2011) OsHMA3, a P1Btype of ATPase affects root-to-shoot cadmium translocation in rice by mediating efflux into vacuoles. New Phytol 189:190-199.

36. Moore KL, Chen Y, van de Meene AML, Hughes L, Liu WJ, Geraki T, Mosselmans F, McGrath SP, Grovenor C and Zhao FJ (2014) Combined NanoSIMS and synchrotron X-ray fluorescence reveals distinct cellular and subcellular distribution patterns of trace elements in rice tissues. New Phytol 201:104-115.

37. Nozoye T, Nagasaka S, Kobayashi T, Takahashi M, Sato Y, Uozumi N, Nakanishi H, Nishizawa NK (2011) Phytosiderophore efflux transporters are crucial for iron acquisition in graminaceous plants. J Biol Chem 286:5446-5454.

38. Roschzttardtz H, Conéjéro G, Curie C, Mari S (2009) Identification of the endodermal vacuole as the iron storage compartment in the Arabidopsis embryo. Plant Physiol 151:1329-1338.

39. Römheld V, Marschner H (1986) Evidence for a specific uptake system for iron phytosiderophores in roots of grasses. Plant Physiol 80:175-180.

40. Sawyer J (2004) Nutrient deficiencies and application injuries in field crops" in IOWA State university (University Extension) IPM 42 Revised July 2004.

41. Sasaki A, Yamaji N, Yokosho K \& Ma JF (2012) Nramp5 is a major transporter responsible for manganese and cadmium uptake in rice. Plant Cell 24:2155-2167.

42. Song Y, Wang Y, Mao W, Sui H, Yong L, Yang D, Jiang D, Zhang L, Gong Y (2017) Dietary cadmium exposure assessment among the Chinese population. PLoS One 12:e0177978.

43. Sui F, Zhao D, Zhu H, Gong Y, Tang Z, Huang XY, Zhang G, Zhao FJ (2019) Map-based cloning of a new total loss-of-function allele of OsHMA3 causes high cadmium accumulation in rice grain. $J$ Exp Bot 70:2857-2871.

44. Pottier M, Oomen R, Picco C, Giraudat J, Scholz-Starke J, Richaud P, Carpaneto A, Thomine S (2015) Identification of mutations allowing Natural Resistance Associated Macrophage Proteins (NRAMP) to discriminate against cadmium. Plant J 83(4):625-637.

45. Yan J, Wang P, Wang P, Yang M, Lian X, Tang Z, Huang CF, Salt DE, Zhao FJ (2016) A loss-of-function allele of OsHMA3 associated with high cadmium accumulation in shoots and grain of Japonica rice cultivars. Plant Cell Environ 39:1941-1954. 
46. Yang M, Zhang Y, Zhang L, et al. (2014) OsNRAMP5 contributes to manganese translocation and distribution in rice shoots. J Exp Bot 65:4849-4861.

47. Takahashi M, Terda Y, Nakai I, Nakanishi H, Yoshimura E, Mori S, Nishikawa NK (2003) Role of nicotianamine in the intracellular delivery of metals and plant reproductive development. Plant Cell 15:1263-1280.

48. Thomine S, Wang R, Ward JM, Crawford NM, Schroeder JI (2000) Cadmium and iron transport by members of a plant metal transporter family in Arabidopsis with homology to Nramp genes. Proc Natl Acad Sci USA 97:4991-4996.

49. Uraguchi S and Fujiwara T (2013) Rice breaks ground for cadmium-free cereals. Curr Opin Plant Biol 16:328-334.

50. Vert G, Grotz N, Dedaldechamp F, Gaymard F, Guerinot M L, Briat J, Curie C (2002) IRT1, an Arabidopsis transporter essential for iron uptake from the soil and for plant growth. Plant Cell 14:1223-1233.

51. Wang P, Chen H, Kopittke PM and Zhao FJ (2019) Cadmium contamination in agricultural soils of China and the impact on food safety. Environ Pollut 249: 1038-1048.

52. Wang P, Yamaji N, Inoue K, Mochida K and Ma JF (2020) Plastic transport systems of rice for mineral elements in response to diverse soil environmental changes. New Phytol 226:156-169.

53. Zhang Y, Su J, Duan S, Ao Y, Dai J, Liu J, Wang P, Li Y, Liu B, Feng D, Wang J, Wang H (2011). A highly efficient rice green tissue protoplast system for transient gene expression and studying light/chloroplast-related processes. Plant Methods 7:30.

54. Zhang Y, Xu YH, Yi HY, Gong JM (2012) Vacuolar membrane transporters OsVIT1 and OsVIT2 modulate iron translocation between flag leaves and seeds in rice. Plant J 72:400-410.

55. Zhao FJ, Tang Z, Song JJ, Huang XY, Wang P (2021) Toxic metals and metalloids: Uptake, transport, detoxification, phytoremediation, and crop improvement for safer food. Mol Plant 14:1-18.

56. Zhao FJ, Wang P (2020) Arsenic and cadmium accumulation in rice and mitigation strategies. Plant Soil 446:1-21.

57. Zhao J, Yang W, Zhang S, Yang T, Liu Q, Dong J, Fu H, Mao X, Liu B (2018) Genome-wide association study and candidate gene analysis of rice cadmium accumulation in grain in a diverse rice collection. Rice 11:61.

\section{Figures}


A

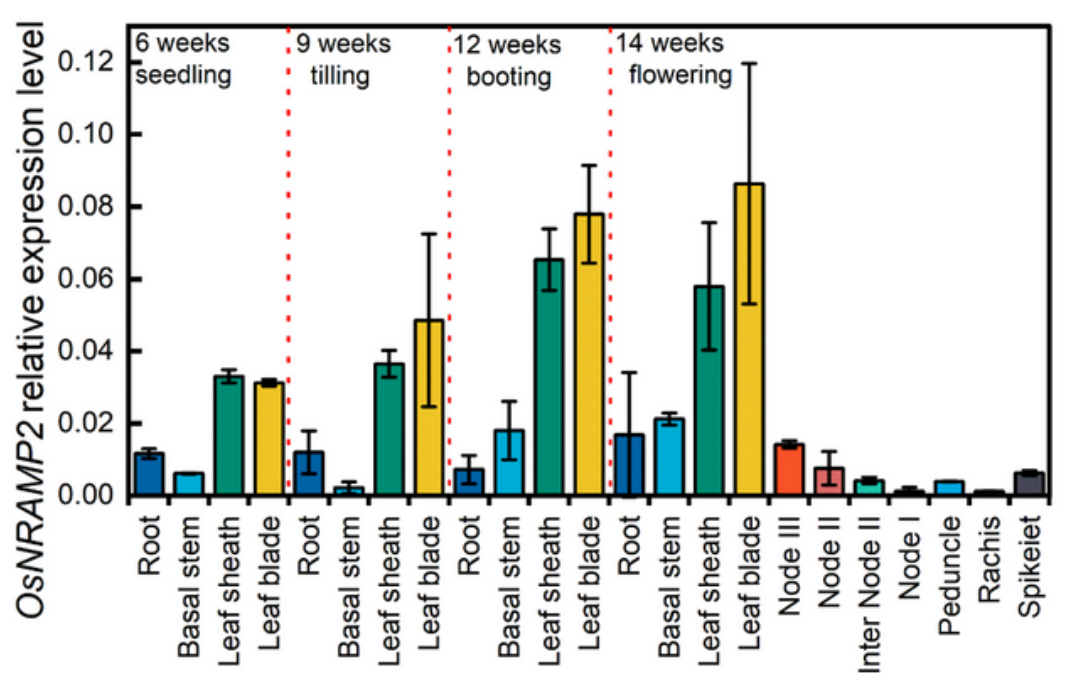

B

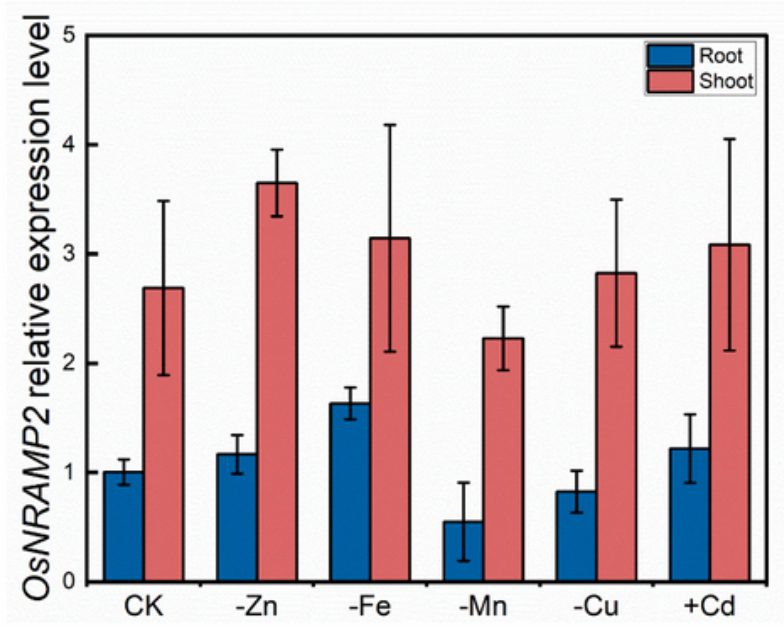

C

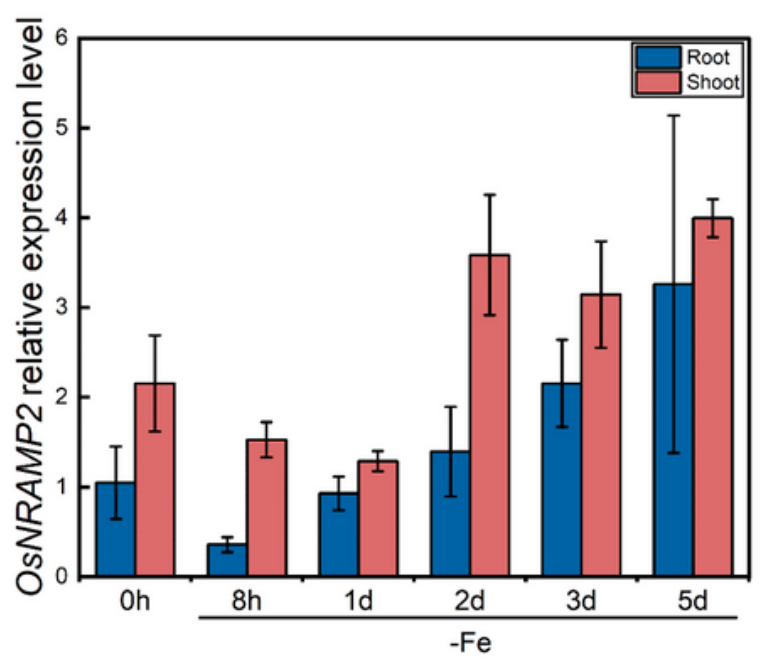

Figure 1

The expression pattern of OsNRAMP2 in rice plants. (A) The expression levels of OsNRAMP2 in different tissues at different growth stages of wild type rice (cv. Nipponbare) grown in a paddy soil; (B) response of OsNRAMP2 expression in roots and shoots to withdrawal of $\mathrm{Fe}, \mathrm{Mn}, \mathrm{Cu}$, or $\mathrm{Zn}$ in the nutrient solution or the addition of $0.5 \mu \mathrm{M}$ Cd for 7 days; (C) response of OsNRAMP2 expression in roots and shoots to 
withdrawal of Fe supply in a time-course experiment. All data are means \pm SD of three biological replicates.

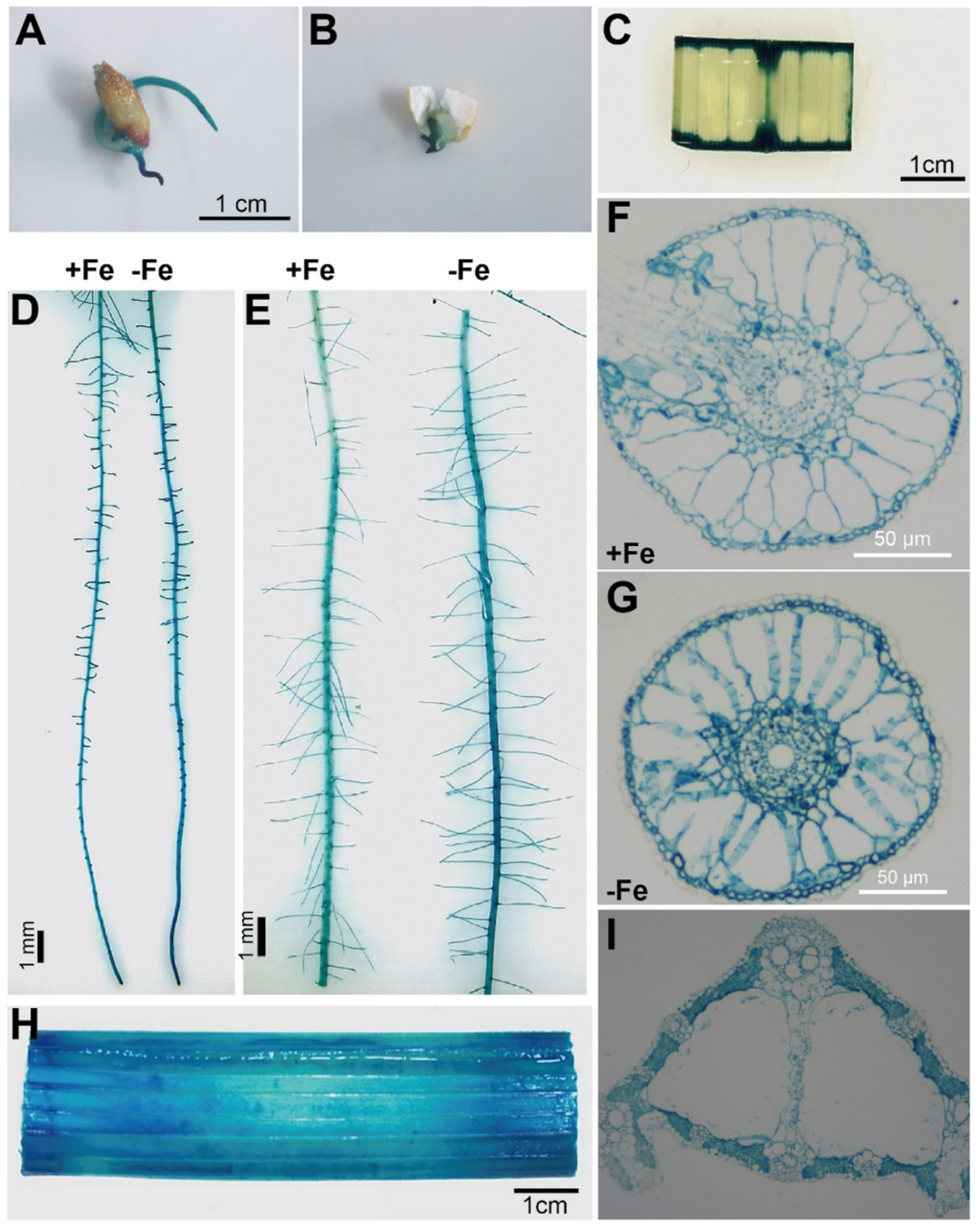

Figure 2

Tissue-specific observation of OsNRAMP2 expression in rice. (A-B) The GUS activity in germinating seeds of 3 days after soaking in water. $(C)$ Leaf and $(H, I)$ leaf sheath of 28-day-old seedling were growth in 
normal condition. the root (D: 0 - $75 \mathrm{~mm}$ from root tip; $\mathrm{E}: 75-150 \mathrm{~mm}$ form root tip) of pOsNRAMP2::GUS transgenic plants under normal $(20 \mu \mathrm{M} \mathrm{Fe})$ or Fe deficiency $(0 \mu \mathrm{M} \mathrm{Fe})$ conditions for 7 days. $(\mathrm{F}, \mathrm{G}, \mathrm{I})$ Cross-sections of the mature root and leaf sheath.

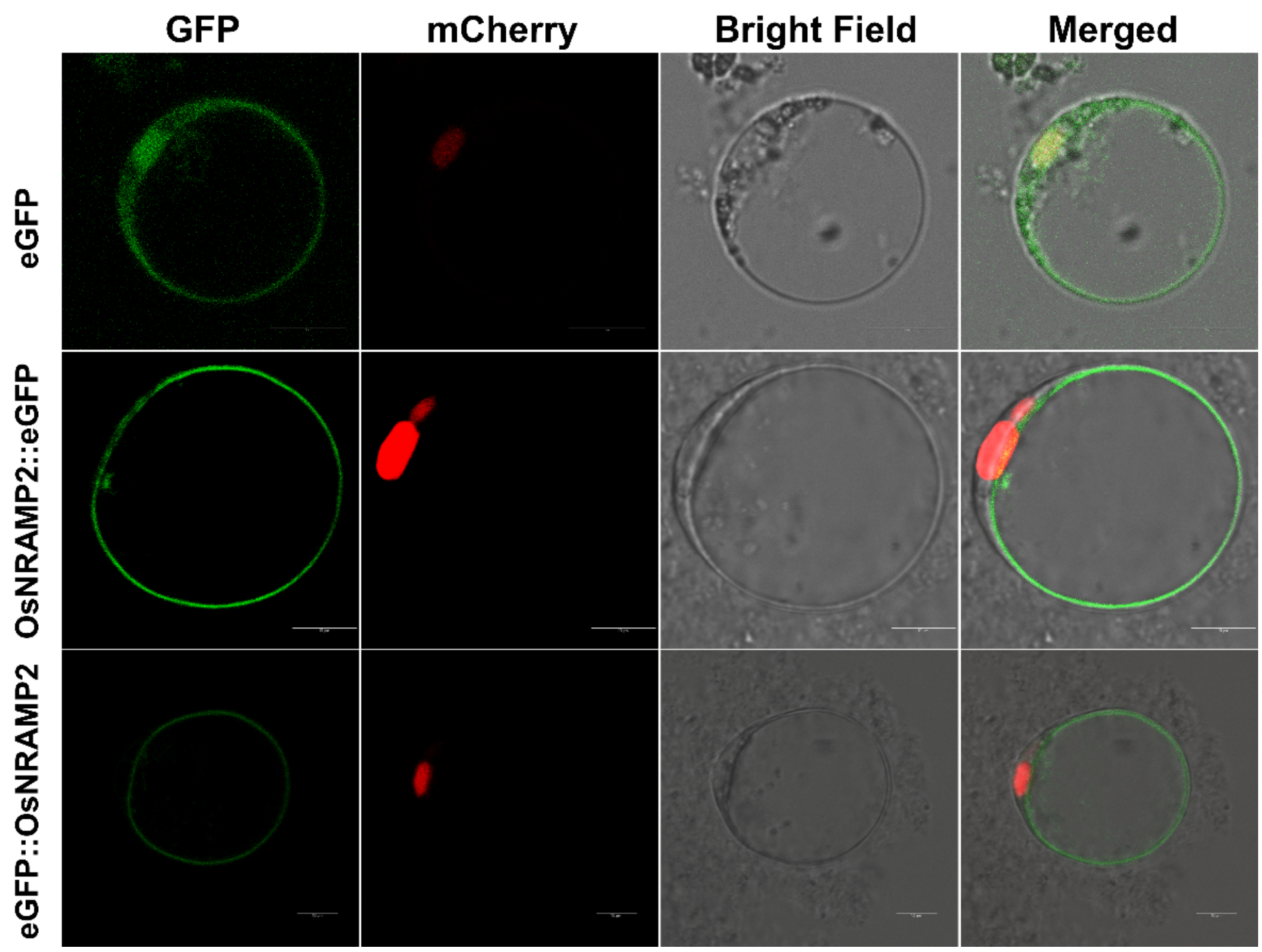

\section{Figure 3}

Subcellular localization of OsNRAMP2 in rice. Representative microscope images of rice protoplasts expressing the enhanced green fluorescence protein (eGFP, top), N-terminal or C-terminal fusion proteins of OsNRAMP2 with eGFP. Left to right: GFP fluorescence, mCherry fluorescence (nucleus marker), brightfield images and merged images. Scalar bar $=10 \mu \mathrm{m}$. 

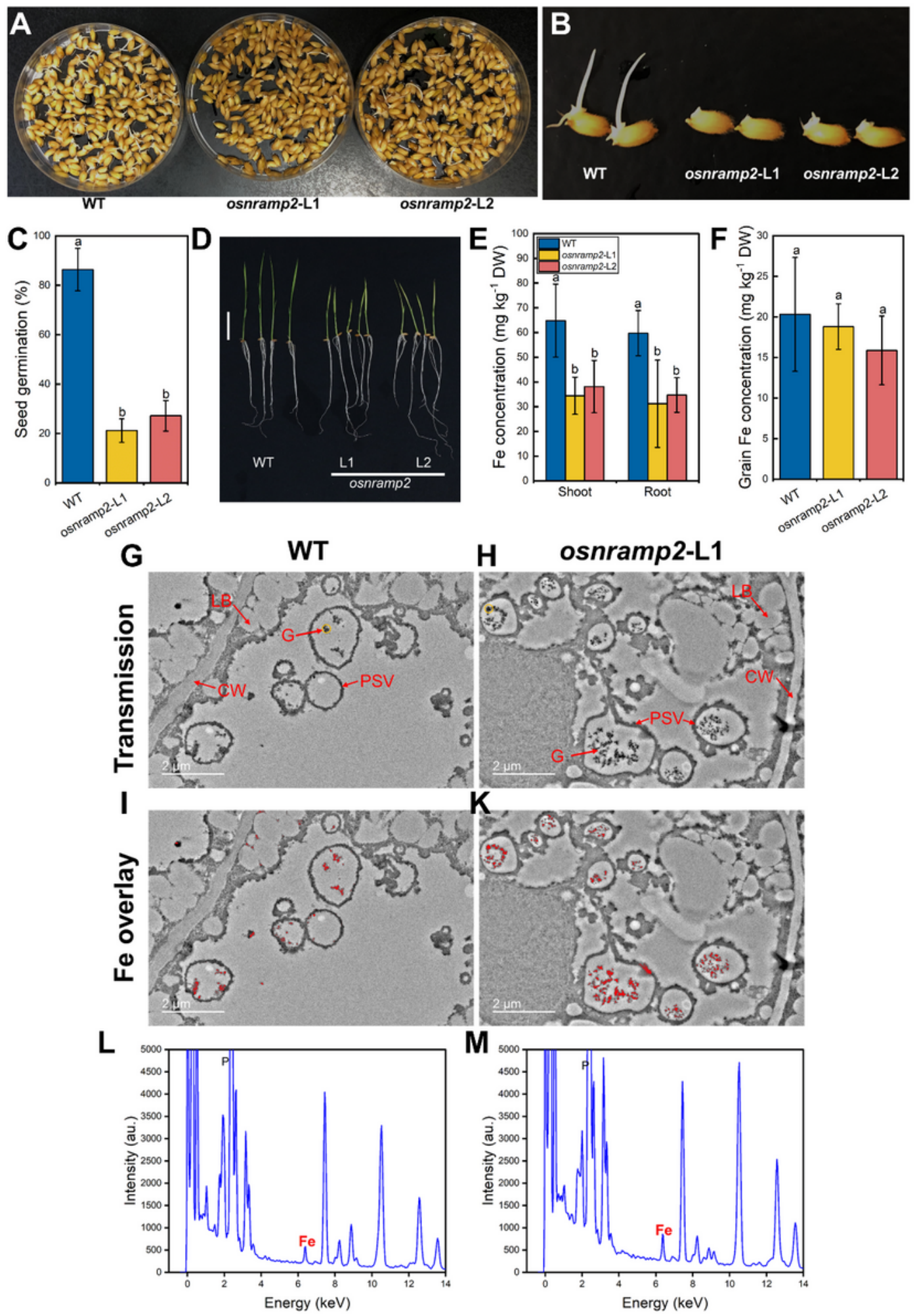

H osnramp2-L1
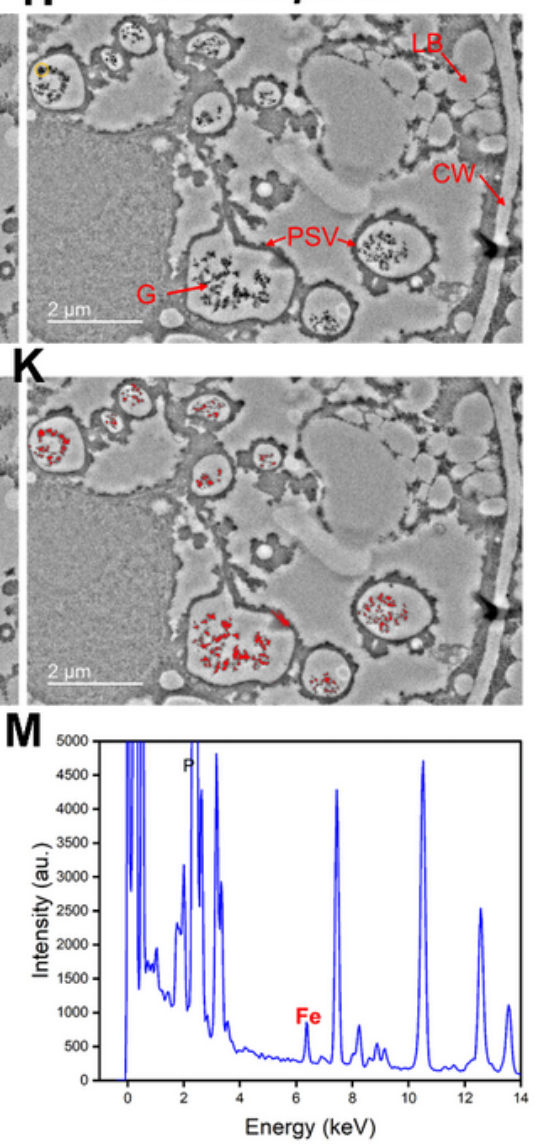

Figure 4

Knockout of OsNRAMP2 delays seed gemination and induces Fe deficiency symptoms in seedlings. (A, B) Growth of osnramp2 mutation lines (L1 and L2) at 3 days after sowing. (C) Germination rates of osnramp2 mutants and wild type at 3 days after sowing. (D) Growth phenotype of osnramp2 and wild type plants under tap water for 8 days after sowing. (E) The concentrations of Fe in roots and shoots of osnramp2 mutants and wild type plants grown in tap water for 8 days. (F) The concentration of Fe in the 
grains. Data are means $\pm S D$ of four biological replicates. Different letters indicate significant difference at $P<0.05$. (G - K) Transmission electron microscopy images of scutellum parenchyma cells of germinating seeds of from wild type $(\mathrm{G}, \mathrm{I})$ or $\operatorname{osnramp} 2(\mathrm{H}, \mathrm{K})$ at 3 days after sowing. $\mathrm{G}$ and $\mathrm{H}$ panels: transmission image; I and K panels: Fe localization (red) obtained through imaging of inelastically scattered electrons (ESI) superimposed on the transmission image. Visible structures are labelled with reference to the Arabidopsis Atlas. CW: cell wall; LB: lipid body; G: globoid; PSV: protein storage vacuole. Empty globoid cavities correspond to globoid compartments from which the globoid crystal has been ejected during sectioning (Lanquar et al. 2005, EMBO J, 24:4041-4051). (L - M) Representative Energydispersive X-ray (EDX) spectra of globoids from wild type (L) or osnramp2 (M) at 3 days after sowing seeds, and the collected areas are indicated by yellow circle in panel $\mathrm{G}$ and $\mathrm{H}$. 
A

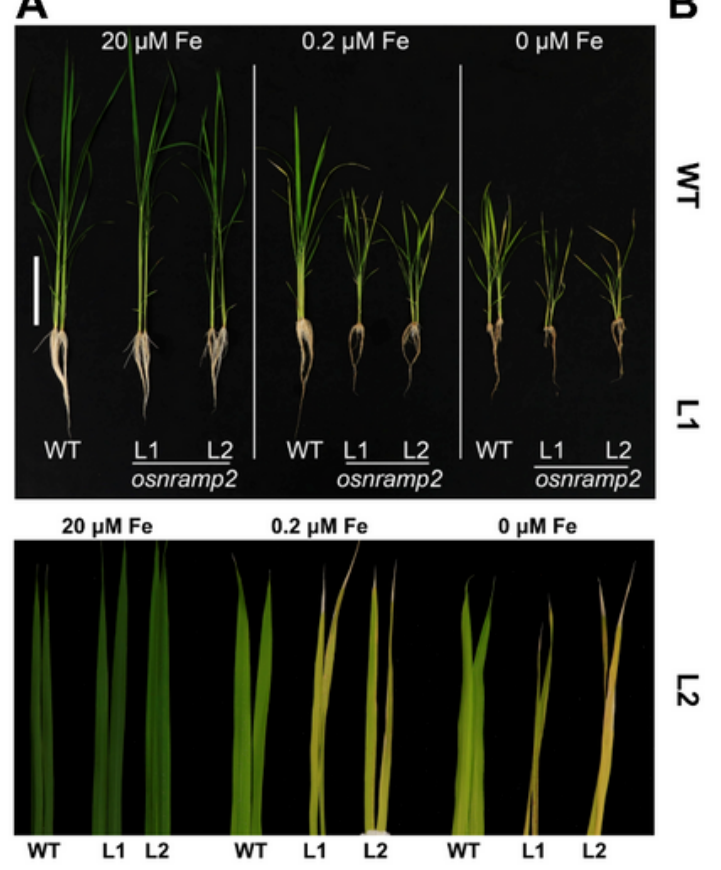

C
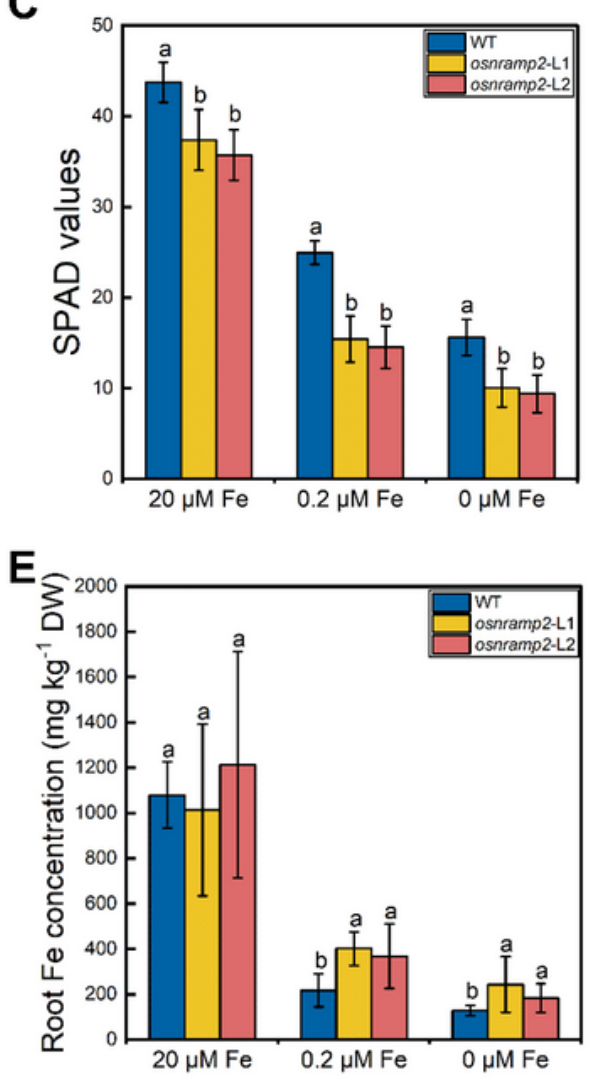

B

$20 \mu \mathrm{M} F \mathrm{Fe}$

$0.2 \mu \mathrm{M} F \mathrm{Fe}$

$0 \mu \mathrm{M} F$

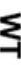

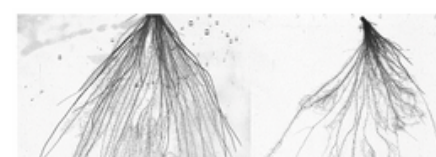

M
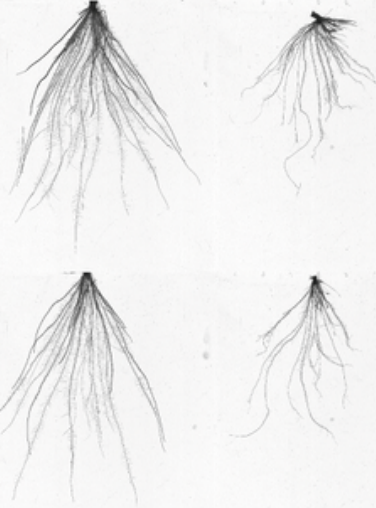

D

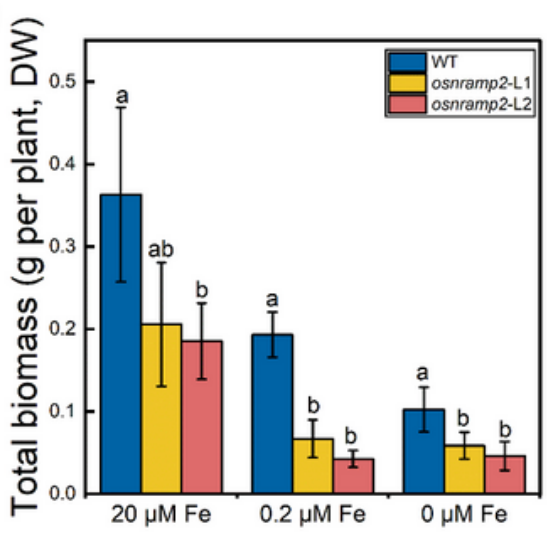

$\mathbf{F}$

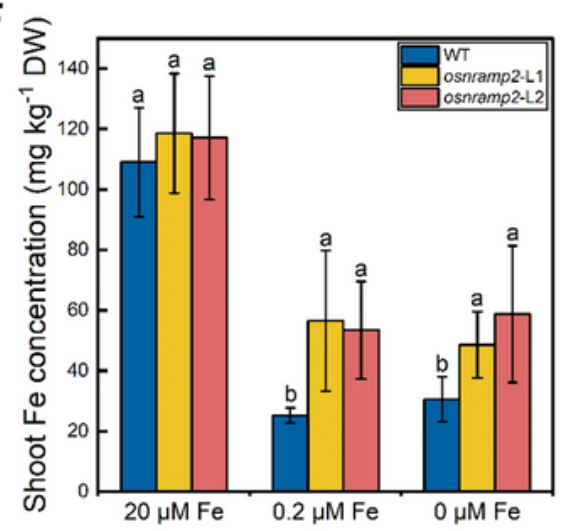

\section{Figure 5}

Phenotypic analysis of osnramp2 mutants and wild type plants grown with different concentrations of Fe supply. (A) The growth phenotype, (B) root phenotype, (C) the SPAD values of the youngest fully developed leaves and (D) total biomass of osnramp2 $(L 1, L 2)$ and wild type. Scale bar $=15 \mathrm{~cm}$. $(E, F)$ The concentrations of $\mathrm{Fe}$ in roots $(\mathrm{E})$ and shoots $(\mathrm{F})$ of osnramp2 mutants and wild type plants. 14-day-old plants of osnramp2 mutants and wild type were grown in a nutrient solution containing $20,0.2$ or $0 \mu \mathrm{M}$ 
EDTA-Fe(III) for 21 days. Data are means \pm SD of four biological replicates. Different letters indicate significant difference at $P<0.05$.
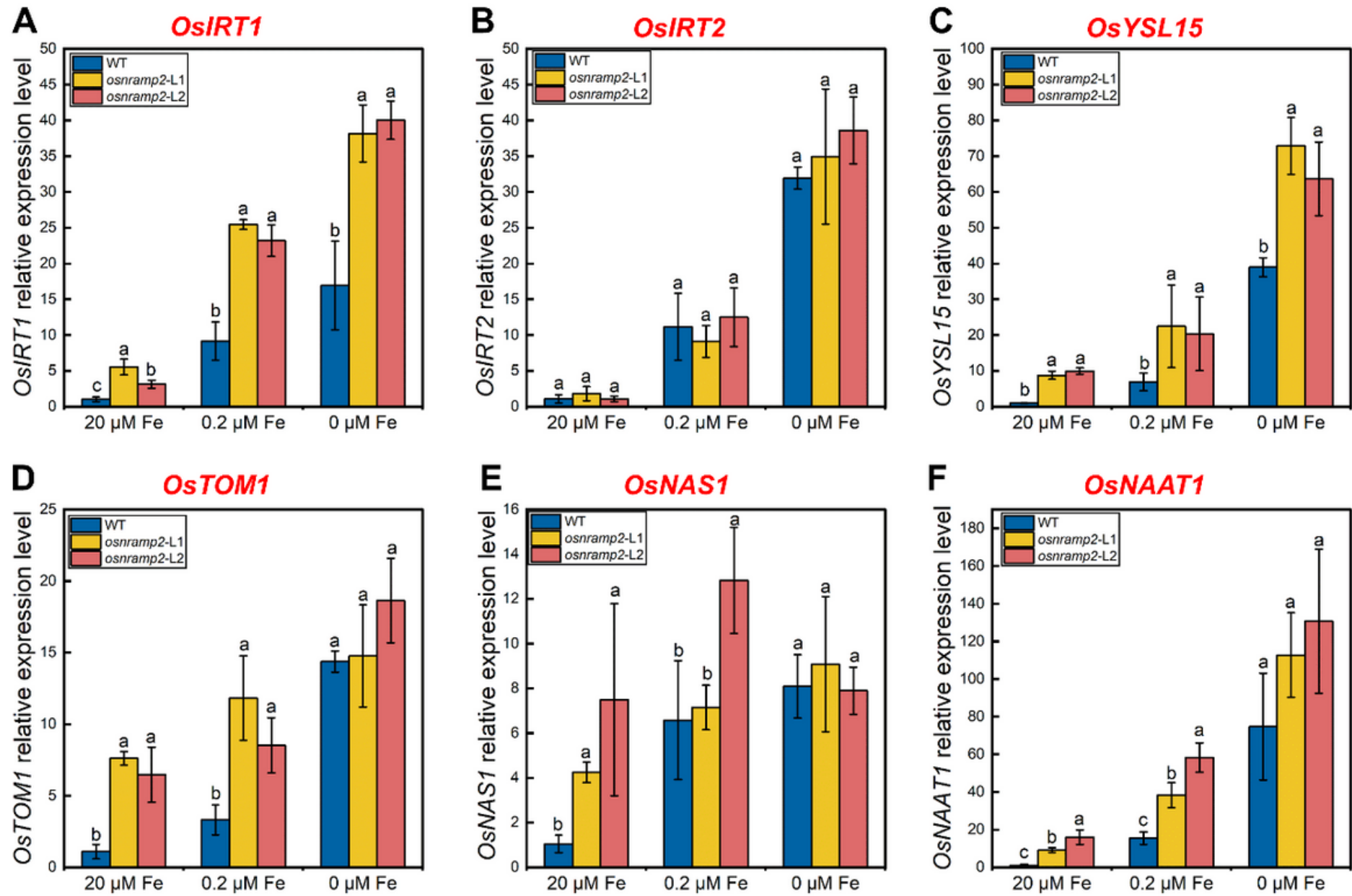

Figure 6

Responses in the expression Fe transport related genes to knockout of OsNRAMP2 under different Fe supply conditions. The expression levels of OsIRT1 (A), OsIRT2 (B), OsYSL15 (C), OsTOM1 (D), OsNAS1 (E), OsNAAT1 (F) in roots of wild type and osnramp2. 14-day-old plants of osnramp2 mutants (L1 and L2) and wild type grown in a nutrient solution containing 0, 0.2 or $20 \mu \mathrm{M}$ EDTA-Fe(III) for 21 days. Data are means \pm SD of three biological replicates. 
A

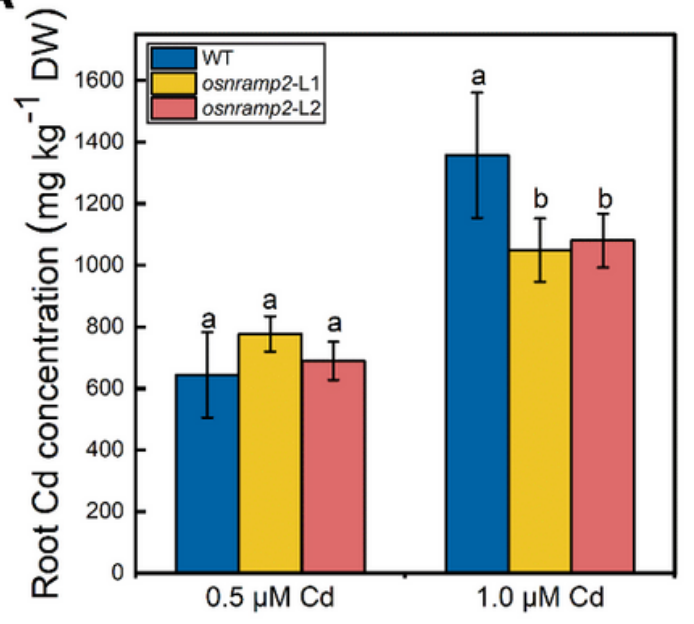

B

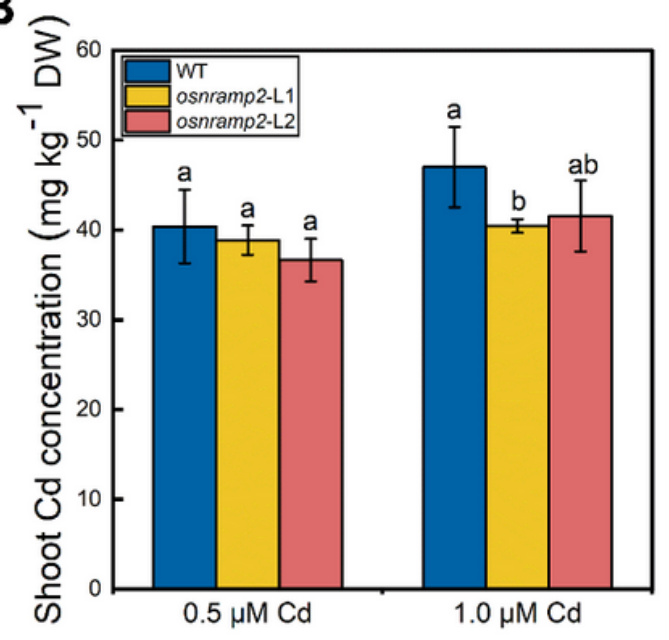

C

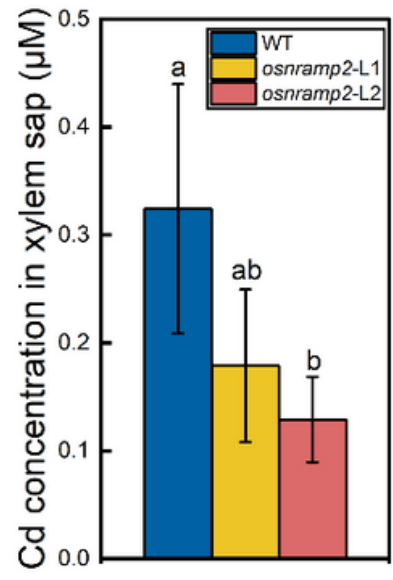

Figure 7

The concentrations of $\mathrm{Cd}$ in roots $(\mathrm{A})$ and shoots $(\mathrm{B})$ of osnramp2 mutants and wild type grown under different Cd concentrations. 21-day-old plants of osnramp2 mutants (L1 and L2) and wild type were grown in normal nutrient solution containing 0.5 or $1.0 \mu \mathrm{M} \mathrm{CdCl}_{2}$ for 10 days. (C) Cd concentration in the xylem sap of 28-d-old plants of two independent lines of osnramp2 mutants (L1 and L2) and wild type exposed to $1.0 \mu \mathrm{M}$ Cd for $12 \mathrm{~h}$. Data are means \pm SD of four biological replicates. Different letters indicate significant difference at $P<0.05$. 
A

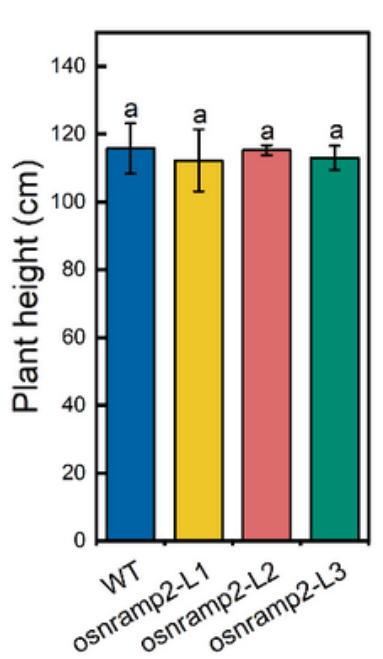

D

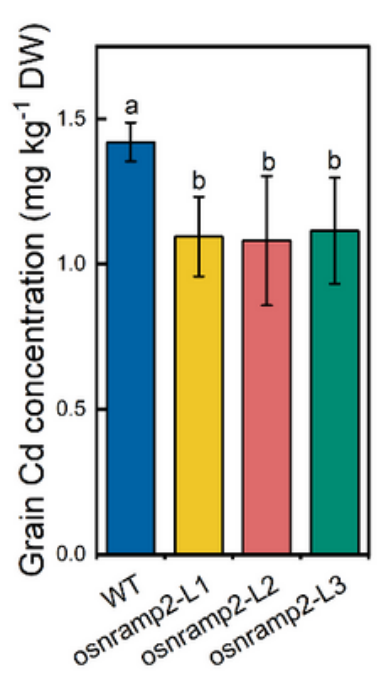

H

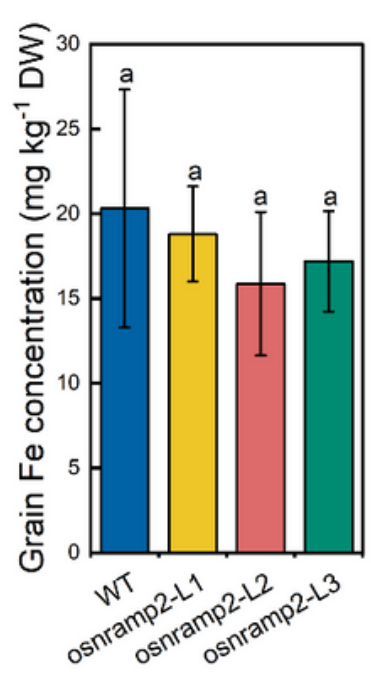

B

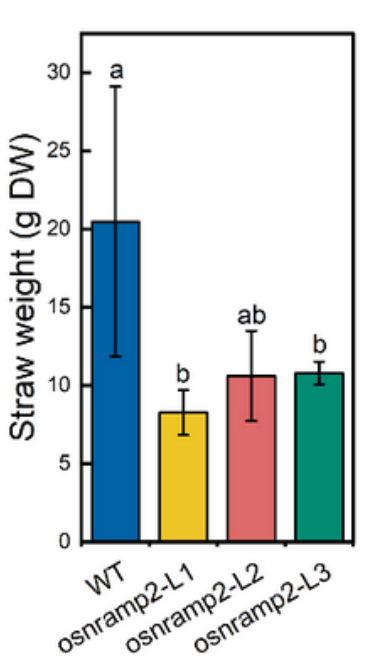

E

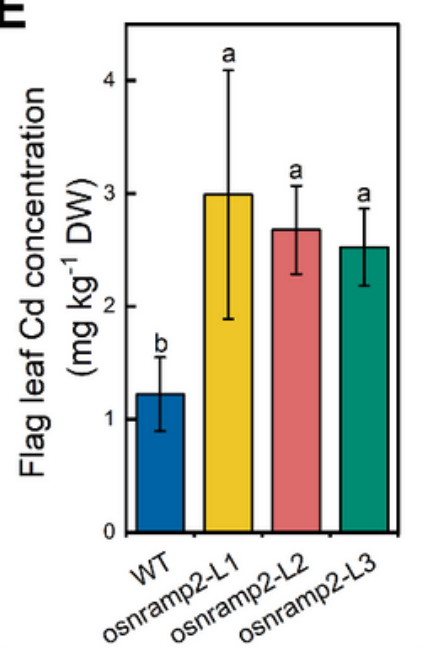

I

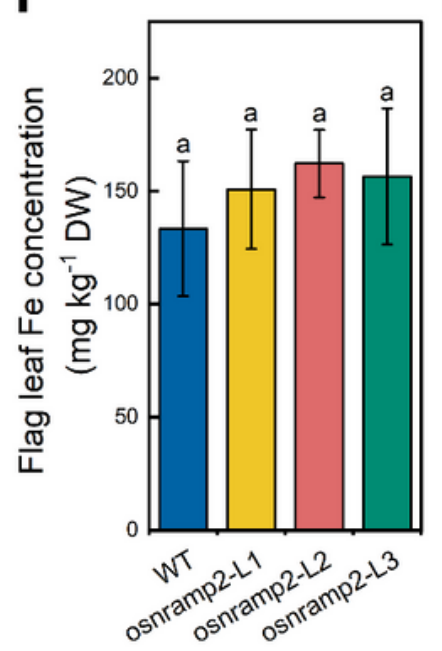

C

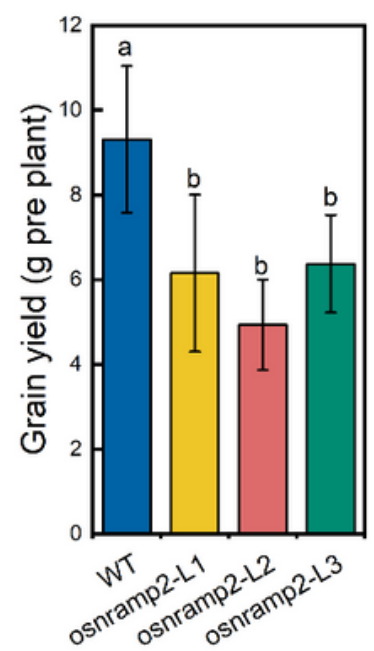

$F$

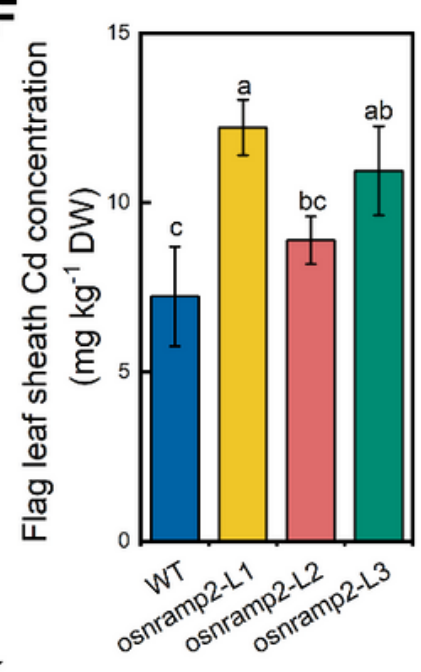

K

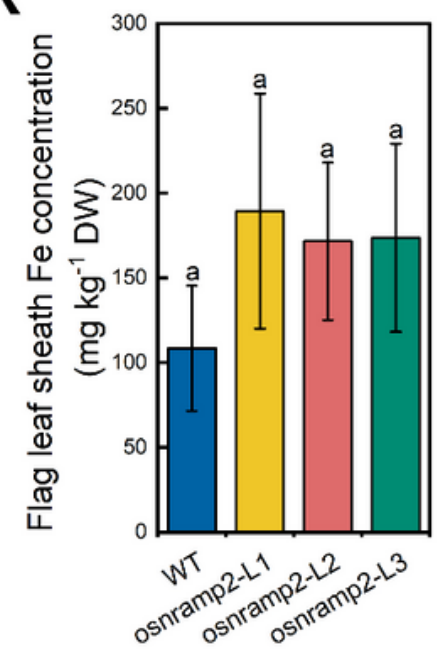

G

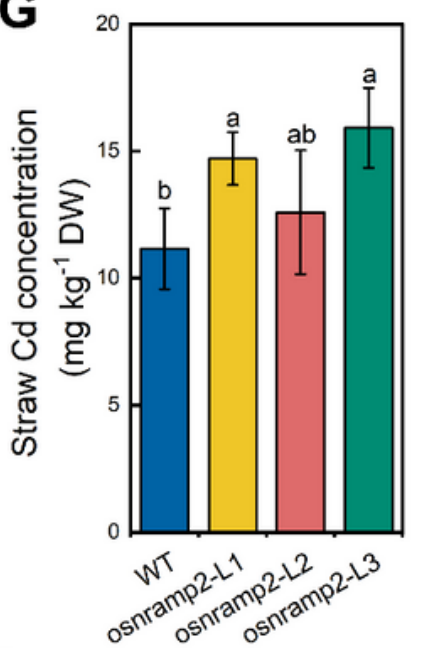

L

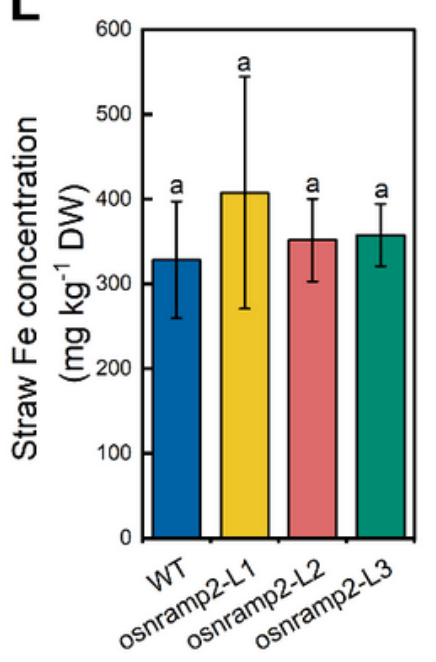

\section{Figure 8}

Growth phenotypes and the concentrations of $\mathrm{Cd}$ and Fe in rice grain (unpolished brown rice), flag leaves, flag leaf sheaths and straws of osnramp2 mutants (L1 - L3) and wild type (cv. ZH11) grown in a pot experiment with a Cd-contaminated soil. (A) Plant height, (B) straw weight and (C) grain biomass of osnramp2 mutants and wild-type. (D - G) Cd concentrations and (H - L) Fe concentrations in rice grain (D, 
$H)$, flag leaves $(E, I)$, flag leaf sheaths $(F, K)$ and straws $(G, L)$. Data are means $\pm S D$ of four biological replicates. Different letters indicate significant difference at $P<0.05$.

\section{Supplementary Files}

This is a list of supplementary files associated with this preprint. Click to download.

- OsNRAMP2Supplementaldata.pdf 